\title{
Wildfire Identification using AI Techniques
}

\author{
S. Jeyabalan \\ RajaRajeswari College of Engineering, Bangalore, Karnataka, India \\ DOI: https://doi.org/10.34293/acsjse.v1i1.3
}

\begin{abstract}
An essential inspiration for building up an online device is to help general well being specialists and crisis responders in settling on educated choices previously, during, and after rapidly spreading fire crises. Need for such frameworks are a lot of critical to dodge the exercise in futility and to lessen the human passings while fierce blaze happens. More automation and inferior extremity activity salvage monetary system on work cost and asset fatigue. It is a practical method of hazard expectation in wildfire.. Toward that end, CDC is building up an online apparatus that uses transient expectations and estimates of smoke fixations and incorporates them with proportions of populace level weakness to help recognize in danger populaces to rapidly spreading fire smoke perils. The instrument will be operationalized on a public scale, looking for information and help from a few scholastic, government, and SLTT Partners. We anticipate that this device will diminish an opportunity to recognize affected networks, help to distinguish and specify weak populaces, better describe populace level openness, and educate execution regarding fitting mediations for those territories influenced by out of control fire smoke perils.
\end{abstract}

Keywords: fire smoke perils, $C D C$

\section{INTRODUCTION}

Rapidly spreading fire scenes represent a noteworthy general well being danger on the planet. Antagonistic well being impacts related with rapidly spreading fires happen close to the consume zone just as in places far downwind because of out of control fire smoke introductions. Well being impacts related with introduction to particulate issue emerging from fierce blazes can extend from gentle eye and respiratory lot aggravation to more genuine results, for example, asthma compounding, bronchitis, and diminished lung work. Ongoing operational estimates of fierce blaze smoke focuses are accessible yet they are not promptly incorporated with data on weak populaces important to recognize in danger networks during rapidly spreading fire smoke scenes. Endeavors are in progress at the Centers for Disease Control and Prevention (CDC) to build up an online instrument that uses transient expectations and conjectures of smoke focuses and incorporates them with proportions of populace level weakness for recognizing in danger populaces to rapidly spreading fire smoke perils. The device will be operational on a public scale, looking for information and help from a few scholastic, government, state, neighborhood, Tribal, and Territorial accomplices. The furnishing clients with admittance to a set-up of planning and show functionalities. A constant weakness evaluation apparatus consolidating normalized well being and introduction datasets, and avoidance rules identified with rapidly spreading fire smoke risks is presently inaccessible for general well-being specialists and crisis respondents. This instrument could reinforce existing situational mindfulness capabilities, and facilitate future reaction and recuperation endeavors during out of control fire scenes. An extensive methodology to alleviate unfavorable well being impacts related fierce blaze calamities requires an exhaustive 
comprehension of populace level introductions to surface smoke PM2.5 focuses. Also, distinguishing weak populaces and puts, and evaluating the sickness trouble related with surface smoke presentations are basic to fortifying general well being readiness capacities for fierce blazes. Appropriately, to help readiness endeavors, a need accentuated by state, nearby, regional, and ancestral (SLTT) well being offices (HDs), is admittance to smoke estimate information, representation instruments, and correspondence reports, just as reconnaissance information on populace well-being and on weak populaces, which can all be made accessible on one data framework and consistently.

\section{LITERATURE REVIEW}

Tragically, such a well-being data framework doesn't as of now exist. Out of control fire scenes represent a critical general well-being danger in the India. The expected effect on well-being, emerging from the fire movement close to dynamic flames just as presentations to surface smoke focuses downwind of the consume territory, speak to a few sweeping results of rapidly spreading fires [1]. Smoke tufts from rapidly spreading fires speak to a mind boggling blend of contamination and its arrangement relies upon a few variables, including the fuel type and winning meteorological conditions. Subsequently, crest organization can change after some time and space and can comprise of a few air contamination, including high groupings of fine particulate issue (PM2.5) and ozone [2].

Well-being impacts related with out of control fire smoke can extend from eye, nose, and throat disturbances to more genuine issues, such as asthma worsening, bronchitis, diminished lung work, and sudden passing. A far reaching technique to moderate antagonistic well being impacts related rapidly spreading fire catastrophes requires a careful comprehension of populace level introductions to surface smoke PM2.5 fixations. Moreover, recognizing weak populaces and puts, and evaluating the infection trouble related with surface smoke presentations are basic to fortifying general well being readiness abilities for out of control fires. Likewise, to help readiness endeavors, a need underscored by state, nearby, regional, and ancestral (SLTT) well being divisions (HDs), is admittance to smoke estimate information, representation devices, and correspondence archives, just as reconnaissance information on populace health and on weak populaces, - which can all be made accessible on one data framework and on an ongoing premise. Shockingly, such a well being data framework doesn't right now exist. In any case which is a reconnaissance stage with an all around structured archive of ecological well being information and easy to use perception capacities, has the vital data innovation framework and skill to embrace such device advancement endeavors [3].

In this original copy, we portray CDC's endeavors to build up an on the web device, which can help SLTT HDs with leading a constant weakness evaluation and recognize in danger populaces to out of control fire smoke impacts. AI (ML) is that the discursive probe of problem solving and information models that PC hypothesis use to drama out a specific trip without employ unequivocal directions, counting on examples and induction. It's viewed as a subset of computerized intelligent. Computer based intelligence figuring create a mathematical model snared in to test data, alluded to as "planning data", so on pick 
conjectures or decisions without being unequivocally redone to show extinct the project. Computer based intelligence computations are used during a wide grouping of usage, for example, email isolating and PC vision, where it's irksome or impracticable to make up an everyday figuring for enough playing out the endeavor. Figure 1 discussed Online Tool Development Effort [4].

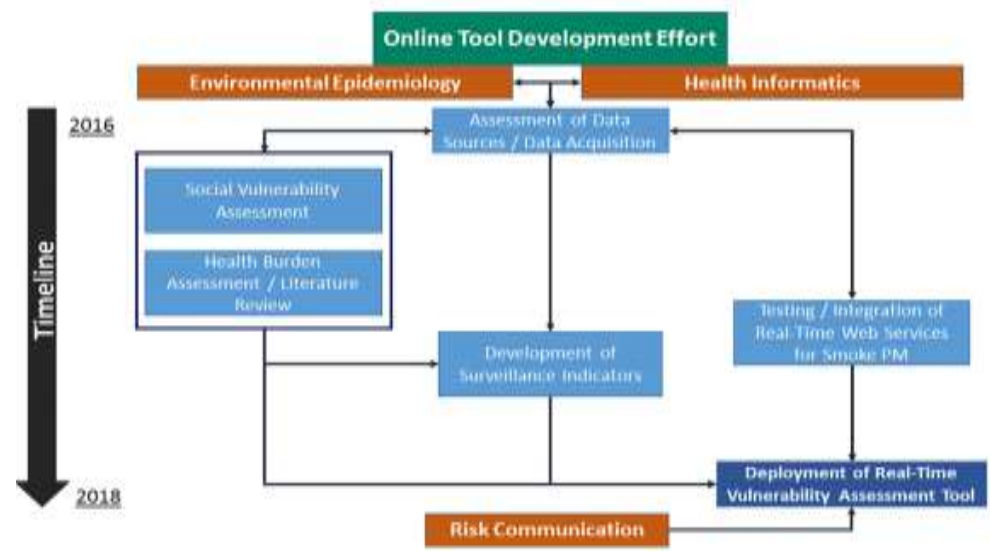

Figure 1: Online Tool Development Effort

Reproduced insight is firmly identified with computational assessments, which rotates around making suspicions utilizing PCs. The assessment of numerical improvement passes on systems, theory and sharpness spaces to the area of AI. Information mining may be a field of study internal AI, and spotlights on exploratory information evaluation through execution learning. In its application all through big business issues, AI is besides hinted as prudent assessment.

\section{Problem Statement}

On 21 February 2019, out of control fire broke call at the Bandipur Tiger Reserve. Not at all like in earlier years, this is frequently the essential time the fierce blaze in Bandipur erupted before on account of the abrupt climatic change and fast move of dry grass and Lantana. More than 10,000 sections of land of timberland in Bandipur region was obliterated. Karnataka saw $350 \%$ more backwoods in 2017. According to the Forest review of India we've around 1333 Wildfires inside the range of three years in Karnataka. Need for such frameworks are significantly imperative to keep away from the misuse of your time and to downsize the human passing while out of control fire happens. More mechanization and less manual movement saves money on work cost and asset weariness. it's a cost viable strategy of hazard forecast in fierce blaze. to save bunches of the human existence in fierce blaze. Principle target early forecast of untamed fire to choose to save the woodlands. to get productive exactness in expectation of hazard recognizable proof in out of control fire. 


\section{MeThodology}

\section{Data Collection}

- We are collecting the wildfire data-set from the forest department in Karnataka.

- The data-set contains many attributes like, dense level, geographical area,, temperature level, etc. In figure 2 shown the data set samples.

\begin{tabular}{|c|c|c|c|c|c|c|c|c|c|c|}
\hline 1 & Dantrit & Geograph Type & & Dent & dom & in Fen & & enent of & & \\
\hline 2 & Bacpitot & 655 & 3 & 0 & II & 269 & $2 n 0$ & 304 & 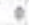 & 23 \\
\hline 1 & Bengluer & seis & 3 & 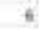 & 33 & 673 & sus & 139 & 2 & 251 \\
\hline a & nengatien & $21 \times n$ & 3 & n & 19 & in & 130 & s.ts & 1 & it \\
\hline$=$ & neigeume & $124+1$ & $z$ & 17 & 937 & 320 & tont & sis & 2 & ma \\
\hline " & neilary & neso & 3 & 0 & 30 & $\omega$ & $m$ & 3.4 & 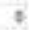 & 28 \\
\hline 7. & Extar & 54 & 3 & 0 & 18 & 36 & 94 & s.9s & is & n \\
\hline 8 & Elopur & 10094 & 3 & 0 & 0 & 12 & a & 6.12 & $\rightarrow$ & 4 \\
\hline 9 & Draneren & S10t & 3 & 45 & 2642 & sat & 294 & $32.4 t$ & $:$ & in \\
\hline 10 & Coikmafit & $\tan$ & 2 & 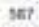 & $203 \pi$ & set & $\operatorname{san}$ & 31.12 & $=$ & ty \\
\hline iu & Detradian & \#⿻心 & 3 & 0 & sn & is & a & 4.35 & . & ans \\
\hline 12 & Oubthine & 450 & 3 & 235 & 1000 & 1596 & 2060 & $62 \pi$ & - & 0 \\
\hline B & bursen & 5924 & 3 & 4 & 39 & 399 & 742 & D.S. & 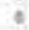 & 209 \\
\hline 14 & Bharwer & 4200 & 2 & 8 & 232 & 43 & ins & 9.64 & 2 & s \\
\hline is & Eatar & sese & 3 & n & o & $m$ & 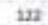 & 2.42 & -4 & 34 \\
\hline 16 & Dutbarte & 1003 & 3 & 0 & $\Rightarrow$ & 200 & 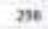 & in & - & at \\
\hline i) & Henesn & 6814 & 2 & a & 30 & su & 1330 & 1392 & - & n \\
\hline 1 & treven & 4823 & 3 & 0 & 14 & 205 & 399 & a.2 & - & si \\
\hline 19 & rodagutt & $\$ 102$ & 2 & 240 & 243 & si & am & 14 & . & e \\
\hline 10 & noler & 120 & 3 & 0 & 9 & 450 & 36 & s.19 & 1 & as \\
\hline it & Koppal & $n$ & 3 & n & 1 & 1 & u & a.ss & 。 & 30 \\
\hline & Mandry & 4961 & 3 & 1 & ตn & 200 & ate & s.23 & 0 & to \\
\hline
\end{tabular}

Figure 2: Sample dataset

\section{Data Preprocessing}

- After collecting the data we are performing the preprocessing to remove the noise information, and redundant data.

- To perform preprocessing we are using the normalization techniques.

\section{Prediction of Fire Incident}

- We are analyzing the data set after preprocessing the system will extract the features.

- Based on the features using the Random Forest model algorithm system will predict the risk in wildfire.

\section{Working Principle}

We combine the features extracted from preprocessed data set. We are applying the splitting the data into train set and test set then we are applying the various machine learning techniques such as Random forest, Logistic Regression and SVM to evaluate the accuracy of predicting the wild fire risks.

\section{Algorithm}

Step1: Load a data set

Step 2: Read the data set and preprocess

Step 3: Extract the low level features

Step 4: Extract the high level features

Step 5: Build the Random forest model. 


\section{RESUlTS AND DISCUSSION}

Information bases that are important to recognize in danger populaces and advance our comprehension of the well being impacts related with rapidly spreading fire smoke are featured in Figure 3(a to f), We chose 11 significant rapidly spreading fires in different Karnataka during 2008-2013 to lead a aeronaut examination. The choice models for hypothese flames depended on the assessed potential unfriendly well being impacts just as accessibility of information to complete undertakings identified with social weakness and well being trouble appraisals. The information accessibility for these flames are clarified in Figure 2 Our appraisal of the 11 rapidly spreading fires (Fig. 4) shows that, zones straightforwardly affected by flames (indicated by the region featured in red in Fig. 4), have networks that rank inadequately for social weakness. Encompassing territories to those legitimately affected by flames, which are meant by a cross-brought forth design, don't straightforwardly endure the worst part of fierce blaze harm however may even now be affected by rapidly spreading fire smoke. While, utilizing a closeness relationship to recognize weak populaces to rapidly spreading fire smoke may neglect transport issues because of meteorology, landscape, and science, it gives an outline of zones liable to be affected by out of control fire smoke. Expectations from air quality models are utilized to comprehend transport of smoke during significant fierce blaze scenes; however data from these recorded model runs are not efficiently documented for community. Toward this end, we depended on recorded model-and screen based air quality information from scholarly and government accomplices. In the wake of looking at results, we chose C-R connections created utilizing a geologically weighted edge relapse — a troupe approach utilizing different air quality data sources. Exploration is being led assessing the effect of out of control fire smoke on human well being with regards to changing populace accomplices and geological areas of accessible proof identified with well being impacts related with rapidly spreading fire smoke showed that there is a powerful relationship between fierce blaze fume and metastasis dismalness, consider intensifications of bronchial asthma and incessant hindering aspiratory malady.

\section{Results Screen Shot}

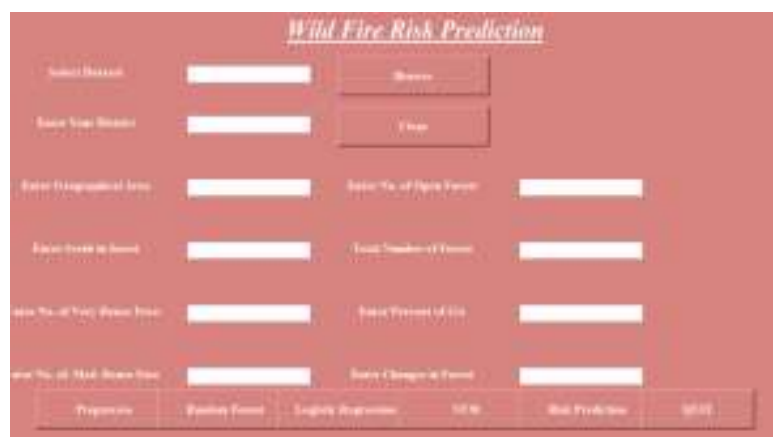

(a)

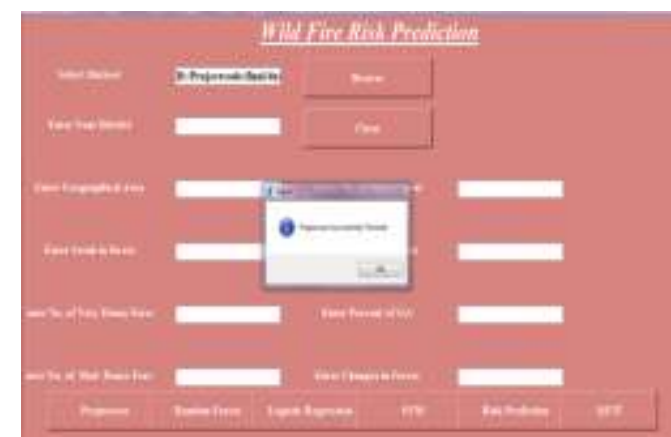

(b) 


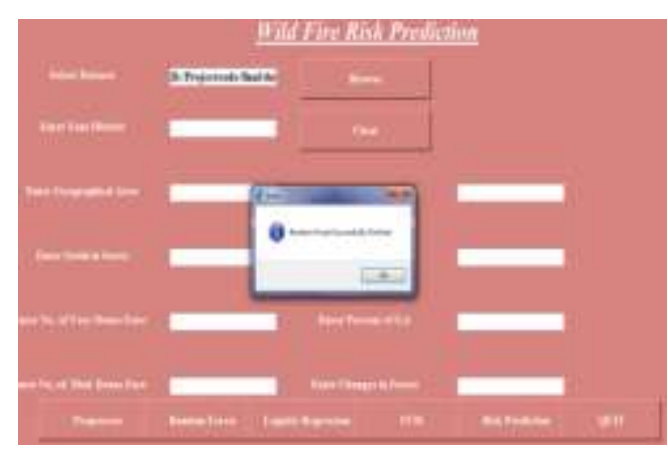

(c)

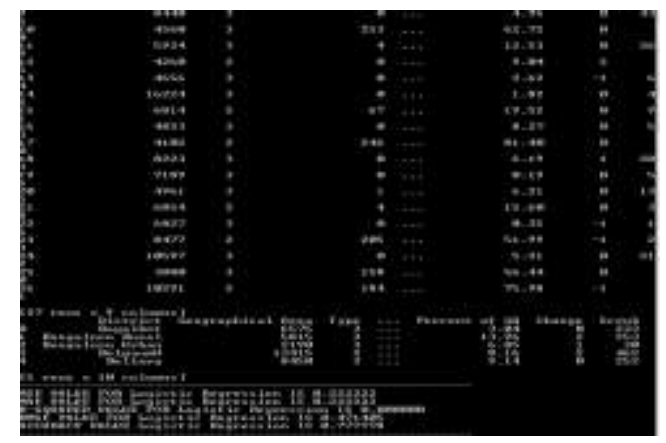

(e)

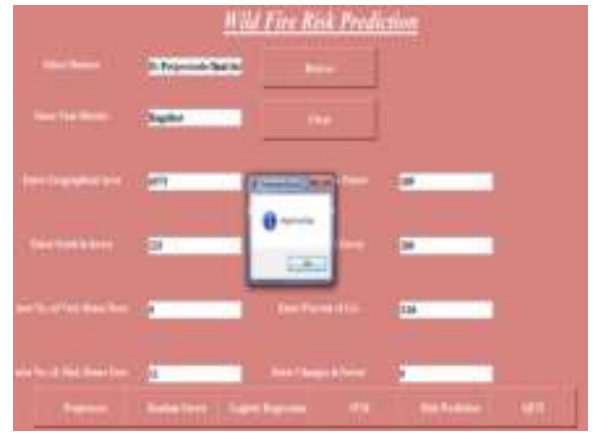

(d)

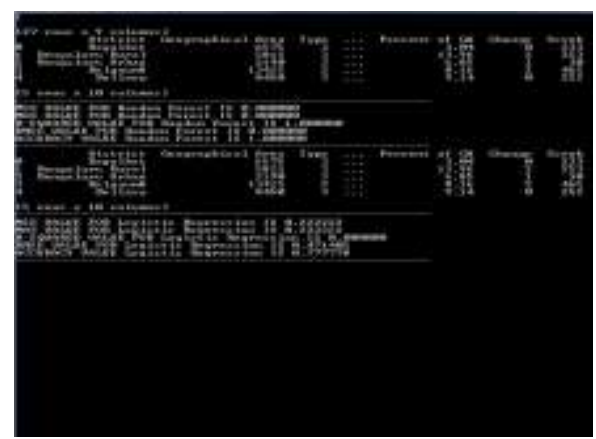

(f)

Figure 3(a to f): Wild Fire Risk Prediction

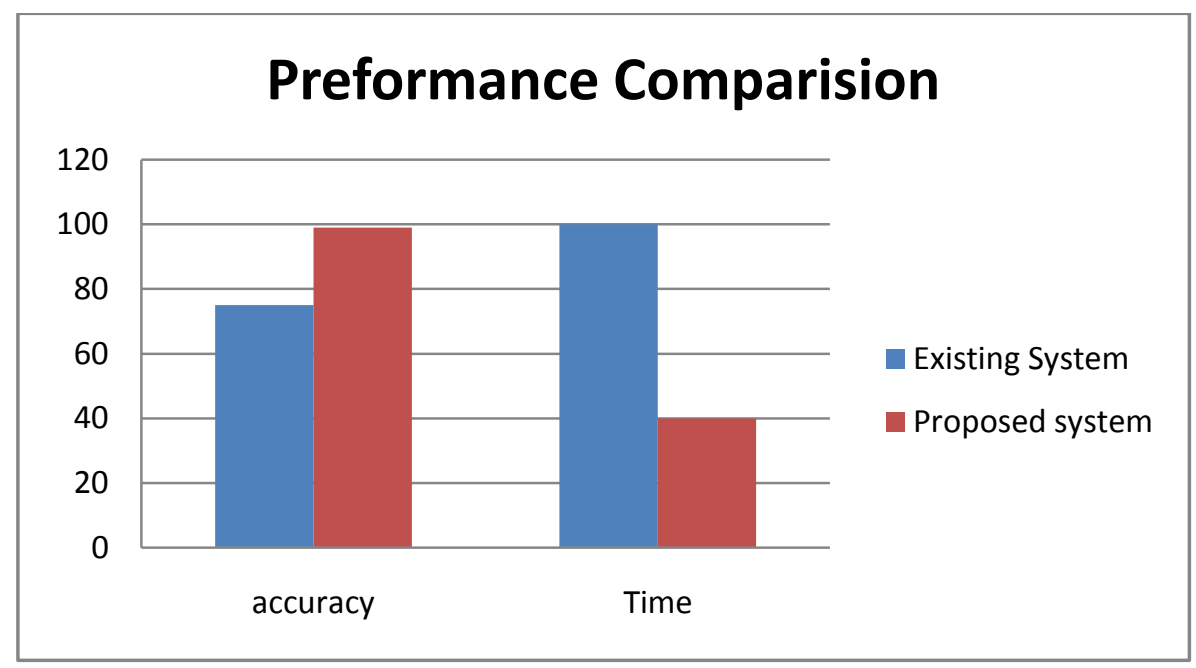

Figure 4: Performance Comparison

\section{CONCLUSION}

An essential inspiration for building up an online device is to help general well being specialists and crisis responders in settling on educated choices previously, during, and after fierce blaze crises. The end of CDC is building up verbunden device which uses transient expectations and figures of vapor fixations and coordinates by proportions which populace plane weakness by assist distinguish in danger populaces to fierce blaze smoke perils. The apparatus will be operationalized on a public scale, looking for information and help from a few scholastic, government, and SLTT Partners. We predict that this apparatus will diminish an opportunity to recognize affected networks, help to distinguish and list weak populaces, 
better describe populace level presentation, and advise execution regarding fitting intercessions for those zones influenced by rapidly spreading fire smoke dangers.

\section{REFERENCES}

[1] Alman, B.L., Pfister, G., Hao, H., Stowell, J., Hu, X., Liu, Y., and Strickland, M.J. "The association of wildfire smokes with respiratory and cardiovascular emergency department visits in Colorado in 2012: a case crossover study," Environ. Health., 15(1), 2016.

[2] Delfino, R.J., Brummel, S., Wu, J., Stern, H., Ostro, B., Lipsett, M., Winer, A., Street, D.H., Zhang, L., Tjoa, T., and Gillen, D.L. "The relationship of respiratory and cardiovascular hospital admissions to the southern California wildfires of 2003," Occup. Environ. Med. 66(3), 2008, pp. 189-197.

[3] Flanagan, B.E., Gregory, E.W., Hallisey, E.J., Heitgerd, J.L., and Lewis, B. “A social vulnerability index for disaster management,” J. Homel. Secur., 8(1), 2011.

[4] Gan, R.W., Ford, B., Lassman, W., Pfister, G., Vaidyanathan, A., Fischer, E., Volckens, J., Pierce, J.R., and Magzamen, S. "Comparison of wildfire smoke estimation methods and associations with cardiopulmonary-related hospital admissions," GeoHealth, 1(3), 2017, pp. 122-136.

[5] Jaffe, D., Chand, D., Hafner, W., Westerling, A., and Spracklen, D. "Influence of fires on O3 concentrations in the western US," Environ. Sci. Technol. 42(16), 2008, pp. 5885-5891. 